\title{
COUNTERFACTUAL EVALUATION. CASE STUDY - ASSESSING THE NET IMPACT OF A PROJECT IMPLEMENTED WITH EXTERNAL FUNDING
}

\author{
Octavia-Andreea ADAM, PhD Student \\ National University of Political Studies and Public Administration \\ Bucharest/Romania \\ octaviaadam@gmail.com
}

\begin{abstract}
Impact evaluation using the counterfactual method is one of the most challenging and efficient evaluation methods. This paper demonstrates the importance, the benefits, the challenges and the frameworks (when should be used) of this method. For a better understanding of counterfactual method, the paper contains an example - a case study of a Norwegian project implemented with non-refundable funds. Compared with other evaluation types the impact evaluation based on the counterfactual method provides complete information on the issues that led either to a positive impact or to a negative impact of the project over the target group. Furthermore this is the best way to measure the net impact of a project or program when the framework provides for the possibility of identifying a control group to distinguish the differences, of course, if they exist, between the moment T0 (before factor interference) and T1 (after factor intervention).
\end{abstract}

\section{Keywords}

Counterfactual evaluation; evaluation; impact evaluation; project 
Society is constantly changing wishing to register results that will lead to a development that meets the needs of citizens. In order to ensure progress, an analysis of what has been implemented, how it has been implemented, what has been achieved and in what proportion has reached the objectives set, what improvements may be made in the future is necessary. In order to generate new results (projects, programs, policies, etc.), this analysis must be systematic, based on concrete and relevant data in the field, in other words - conducting an evaluation. A society in search of an evaluation is one that prefers rational thinking and critical research of tradition, ideology and prejudice (Shaw, Greence and Mark 2006, 143).

According to the definition provided by the World Bank, impact evaluation is a particular type of evaluation that attempts to answer questions of cause and effect. Unlike general evaluations, which can answer many types of questions, impact evaluation are structured around a single particular type of question: What is the impact (or causal effect) of a program on an outcome of interest? (Gertler, Martinez, Premand et all. 2011, 7-8). It seeks changes that can be directly attributed to the program, therefore, the focus falls on causality and attribution, being the distinguishing sign of the impact evaluation. Impact evaluation is of two types: impact evaluation based on program theory and counterfactual impact evaluation.

The first type of impact evaluation I have outlined above, the one based on program theory, involves examining the assumptions underlying the causal chain from inputs to results and impact. In other news, an impact evaluation based on program theory answers the question: why does a particular program work?

The impact evaluation based on program theory is based on a set of key principles, these are: program theory (the causal chain); understanding the context; anticipation of heterogeneity; rigorous impact evaluation using a credible counterfactual; rigorous realization of a factual analysis; the use of mixed methods (White 2009, 7).

An impact evaluation, the second type of evaluation, is based on a counterfactual analysis that compares what would have happened in the absence of an intervention on the actual results that appear during the 
intervention. The impact evaluation can also compare the results of a particular intervention with those of a different intervention.

Figure 1 presents, in the form of a scheme, which involves the counterfactual evaluation: The intervention takes place in time $t$, when the level of our interest result is Yt. After the intervention, the result of the interest becomes $\mathrm{Y} 1 \mathrm{t}+1$, while it would have been only $\mathrm{Y} 0 \mathrm{t}+1$ without the intervention. The latter is the counterfactual value of $\mathrm{Y}$.

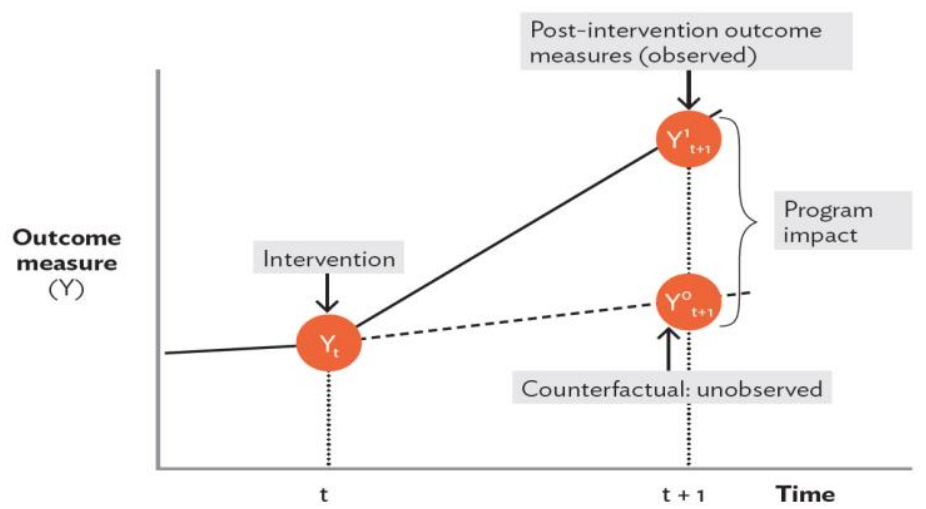

Source : White, H., Raitzer, A., D., Impact Evaluation of development intervantions

You might wonder why should you use this kind of evaluation because is not an easy or a cheap one. Identifying correctly the problems that programs are facing in implementation stage that blocks the impact expected in the beginning takes time and resources. Currently our objective is to implement programs and strategies cost-efficient oriented, that have clear and sustainable impacts.

Is it worthy? Sure, it does if you really want to make a change. It is better to use a costly method of evaluation if it helps you to reduce the risk of allocating money in a field/ aria/direction who cannot reach the impact expected. For example, an evaluation based on objectives can tell you if the program was successful or not by checking if, the activities took place but that does not mean 
the program had a real positive impact for the target group/community. In this case, what will be the point of keep implementing it?

Of course, there are a lot of challenges that comes with this type of evaluation but in the same time there are several benefits, provides answers: on the effects on short, medium and long-term outcomes; of the causal link between an intervention and outcomes; where interventions are made effective; what drives change in the program/ strategy.

One of the biggest challenges in this type of evaluation is the identification of the control group. Why is it challenging? Because its characteristics, from a statistical point of view, must be as similar as "faithful" with those of the group on which the estimators / factors act before the intervention. The more similar the two groups are, the more a real, clear picture can be obtained about the impact within the program / project.

Although it is impossible to identify a group identical to the main one, even biologically speaking, there are three criteria that must be taken into account when making the selection in order for it to be valid. First, the average characteristics of the treatment group and the comparison of the group must be identical in the absence of the program (for example, age, area of origin, school situation, financial situation, etc.). Second, treatment should not affect the comparison group, directly or indirectly. Third, the results of the units in the control group should change in the same way as the results in the treatment group, if both groups received the program (or not). In this respect, the treatment and control groups should be reacted to the same program (Gertler, Martinez, Premand et all 2011, 52).

Another big challenge in using this type of evaluation is that whereas the outcomes of the program being evaluated are observable (although not always easily identified or measured), the outcomes in the absence of the program, at least in principle, are counterfactual and not observable. This situation requires that the evaluation design provide some basis for constructing a credible estimate of the outcomes for the counterfactual conditions. In order to identify the most suitable counterfactual, the evaluation study must be designed to account for the circumstances of the particular program being evaluated, the nature of its target population, the outcomes of interest, the data available, and 
the constraints on collecting new data. As a result, it is difficult to define a 'best' design for impact evaluation a priori. Rather, the task for the evaluator is to identify the best design for a particular program under the particular conditions when the evaluation is undertaken (Cummings 2006, 7).

Where can be used counterfactual evaluation? It should be used in the policy making process. The last stage of the policy making process is "Policy evaluation and change" - where the main goal is to make sure the programs that were created are working properly and are meeting the requirements, if it will keep running or the funding will be stopped. When it comes to make decisions whether to continue or not with a program, you need facts, real data all collected from the field (qualitative or quantitative) and the perfect frame is impact evaluation. Especially when it comes to public policies targeting social aria like (NEETS, disadvantaged children, insertion on the labour market of young people, training courses, homeless people etc.), it is easy to measure the impact with counterfactual evaluation.

Another pro argument for using this type of evaluation in the process of policymaking, can generate unexpected results when you have control and treatment group. On the other hand, you have to be aware that it can provide information only in a certain time, it is unrepeatable.

In the same time, counterfactual evaluation is needed (if can be used) when you do not have updated information and you have nothing to compare before T1. The policy has a positive impact compared with what? How can you know if what you measure are results from the policy or other factors had interfered?

For a better understanding of how counterfactual evaluation works, bellow is a very good example where you can see the theoretical part put into practice (the steps, the challenges, the approach). The following case study even if is about a project, it is a very good starting point for an evaluation on a bigger scale.

\section{CASE STUDY}

The overall objective of the project is to increase the school integration and social inclusion for 400 children at risk in Bucharest, by providing extracurricular educational programs and psycho-pedagogical counselling. 
The main activities of the project consisted in organizing psycho-pedagogical counselling sessions (self-knowledge, health education, emotions and communication, school and professional orientation), training sessions (dance, painting, sports and theater), parenting counselling sessions. / tutors / legal representatives of the children from the project, group information sessions, addressed to teachers, training experts, counsellors from the educational units from which the target group is selected, mountain and sea camps for children. The purpose of the evaluation is to determine the impact that the activities of the project have on the target group.

\subsection{Evaluation questions}

\begin{tabular}{|c|c|c|c|}
\hline \multicolumn{2}{|r|}{ Evaluation questions } & Indicators & Collection methods \\
\hline 1. & $\begin{array}{l}\text { Did the project } \\
\text { activities have an } \\
\text { impact on the } \\
\text { target group? }\end{array}$ & $\begin{array}{l}\text { - the level of knowledge } \\
\text { before starting the } \\
\text { activities } \\
\text { - level of knowledge after } \\
\text { completing activities }\end{array}$ & $\begin{array}{l}\text { Questionnaire } \\
\text { Observation } \\
\text { Interview }\end{array}$ \\
\hline 2. & $\begin{array}{l}\text { Will the results of } \\
\text { the implementation } \\
\text { of the project } \\
\text { continue after its } \\
\text { completion? }\end{array}$ & $\begin{array}{l}\text { - the level of knowledge } \\
\text { before starting the } \\
\text { activities } \\
\text { - level of knowledge after } \\
\text { completing activities }\end{array}$ & $\begin{array}{l}\text { Questionnaire } \\
\text { Interview }\end{array}$ \\
\hline 3. & $\begin{array}{l}\text { Are there any } \\
\text { external factors } \\
\text { that have } \\
\text { influenced the } \\
\text { fulfillment or non- } \\
\text { fulfillment of } \\
\text { objectives? }\end{array}$ & $\begin{array}{l}\text { - The number of factors that } \\
\text { have positively influenced } \\
\text { the achievement of } \\
\text { objectives } \\
\text { - The number of factors that } \\
\text { negatively influenced the } \\
\text { achievement of goals }\end{array}$ & $\begin{array}{l}\text { Questionnaire } \\
\text { Observation }\end{array}$ \\
\hline
\end{tabular}




\subsection{Methodology}

\section{Target group selection}

The target group consists of 15 beneficiaries, representing $9 \%$ of the people enrolled so far (May 2018) in the project. The selection was randomly made from the database using a free online selection. I chose this approach because I could not identify a number of common factors (age, educational unit, etc.) so that, by taking them into account, other equally important factors (material situation, structure family, etc.) will be excluded.

Regarding the control group, each beneficiary is assigned a "correspondent", the main factors that were taken into account are: age, unit of education, gender.

\section{Tools used}

In the evaluation were used both the qualitative tools - the interview and the observation, as well as the quantitative tools - the questionnaire.

The questionnaire was used on both the target group and the control group. This was applied for both groups twice - at the beginning and at the end of the activities - in order to measure the level of knowledge and observe the possible differences.

The questionnaires were self-administered, thus eliminating the filtering of information by another person - the investigative operator. At the same time, in the absence of an outsider - the operator - subjects are likely to be more willing to answer questions (Cummings 2006, 232), especially as project beneficiaries are children and the presence of an unfamiliar person is causing some discomfort. Also, self-administration of the questionnaires reduced the time and resources.

The questionnaire was composed of several types of questions, even graphical images, because it was conceived on the basis of the course supports that the beneficiaries were going to use through within the project, namely: the human body's secrets, the feast of emotions, the fun math, the art of watercolor, fitness and nutrition, entrepreneurship and financial education, communication, nature secrets and graphics. Also, the questions were adapted to the age and needs of the beneficiaries. 
In this evaluation, the observation is systematized (explicitly uses plans for selecting, recording and coding the data), fieldwork (on the site of activities) and participatory (the researcher is present in the collectivity studied and participates as much as possible in activities, integrates into the community).

A series of four interviews were conducted, three of them with project trainers and the fourth with one of the counsellors. This option was chosen because there are eight trainers and two counsellors, and the beneficiaries have 16 hours of training and only 2 hours of counselling.

\subsection{Evaluation Report}

Validity of the control group

In the first chapter, in the presentation of the theoretical framework, it is specified that a control group that can be considered valid must meet a minimum of three criteria / characteristics. The first aspect refers at the mean of characteristics of the treatment group and the mean of characteristics the control group - it should be the same in the absence of the program. In the following, these characteristics will be analysed: gender, age and educational unit.

a. Gender

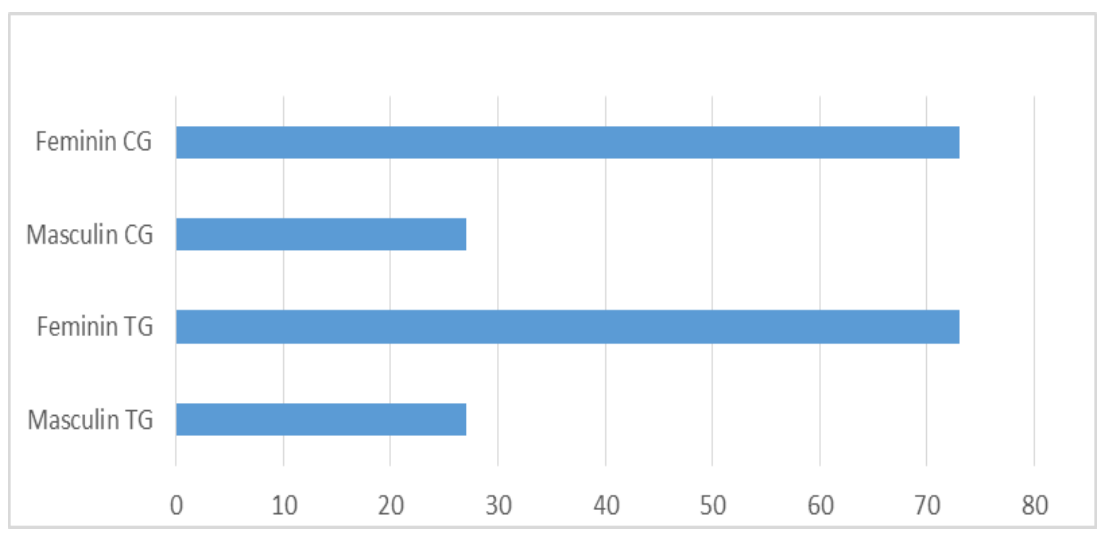


As can be seen, both in the treatment and control groups, the percentages, in terms of gender, are the same. It can also be noticed that the proportion among female participants is approximately three times higher than the one of male participants.

b. Age (mean)

\begin{tabular}{|l|l|}
\hline Control group & $12,1(3)$ \\
\hline Treatment group & $12,1(3)$ \\
\hline
\end{tabular}

The mean age in both the treatment group and the control group is the same. Thus, a balanced participation is observed in both the control group and the treatment group.

c. Educational unit

\section{Treatment group}
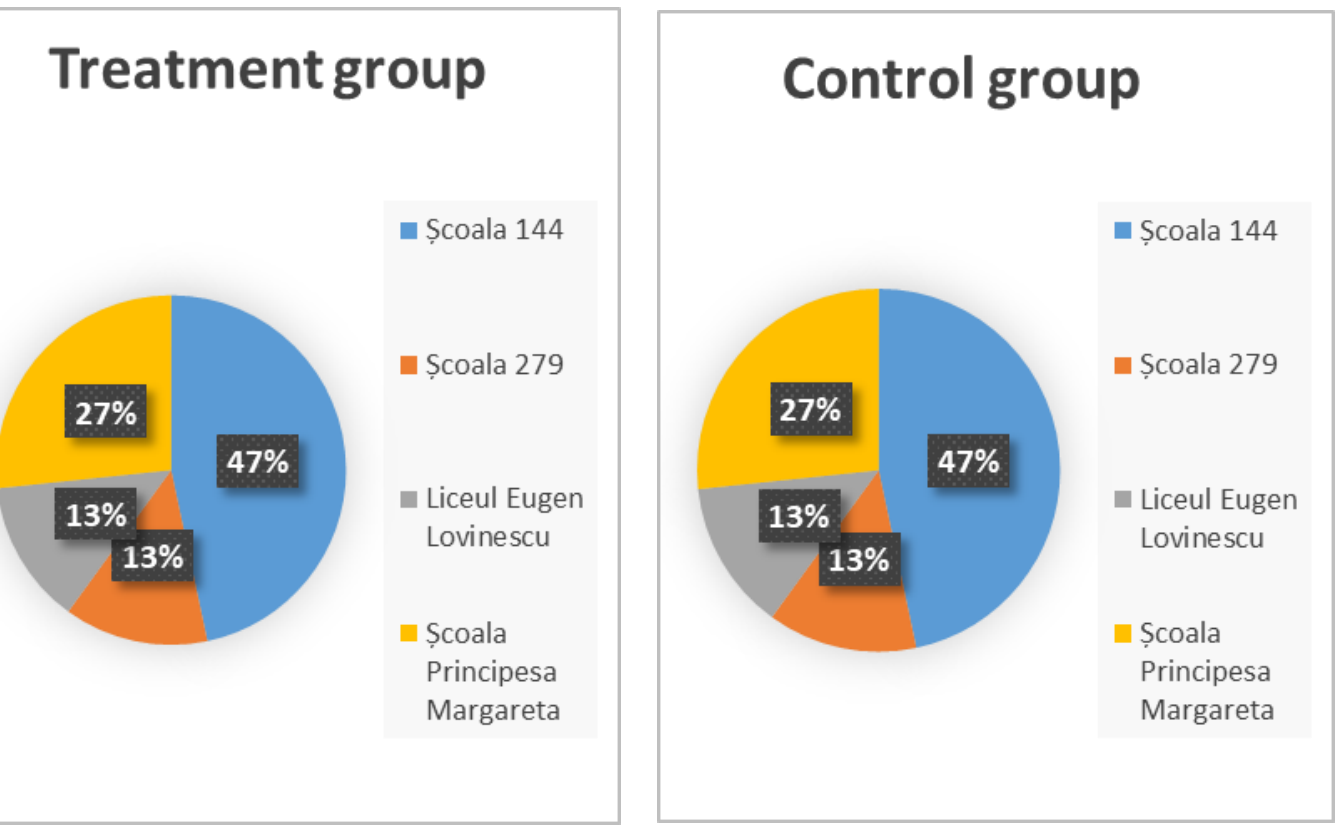
Concerning the educational unit, in the two groups the percentages are the same because the selection of the control group was made in the mirror according to the three aspects presented above: gender, age and educational unit.

The second aspect assumes that the treatment does not have direct or indirect effects on the control group. In the present case, training and counselling classes took place at the premises of the partner organizations and not in the educational establishments. Thus, there were no direct or indirect effects of the courses on the control group.

The third aspect refers to the fact that the same results should be obtained in both groups if the factor would apply.

\begin{tabular}{|l|l|l|l|l|l|}
\hline $\begin{array}{c}\text { I am aware of what I feel in } \\
\text { different situations }\end{array}$ & $\begin{array}{l}\text { To a } \\
\text { small } \\
\text { extent }\end{array}$ & $\begin{array}{l}\text { To } \\
\text { some } \\
\text { extent }\end{array}$ & $\begin{array}{l}\text { To a } \\
\text { moderate } \\
\text { extent }\end{array}$ & $\begin{array}{l}\text { To a } \\
\text { great } \\
\text { extent }\end{array}$ & $\begin{array}{l}\text { To a } \\
\text { very } \\
\text { great } \\
\text { extent }\end{array}$ \\
\hline Treatment group T0 & $14 \%$ & $13 \%$ & $20 \%$ & $40 \%$ & $13 \%$ \\
\hline Treatment group T1 & $0 \%$ & $0 \%$ & $36 \%$ & $46 \%$ & $18 \%$ \\
\hline Control group T0 & $18 \%$ & $0 \%$ & $23 \%$ & $24 \%$ & $35 \%$ \\
\hline Control group T1 & $20 \%$ & $0 \%$ & $33 \%$ & $27 \%$ & $20 \%$ \\
\hline
\end{tabular}

After analysing the answers given by the participants in the two groups to the statement "I am aware of what I feel in different situations", it is noticed that the participants in the treatment group became more aware of what they feel in different situations. If at the time $\mathrm{T} 014 \%$ of them stated that they were aware of what they felt very little and $15 \%$ of them to a small extent at the time of $\mathrm{T} 1$ none of the respondents stated that they were aware of what they felt in some cases "To a very small extent" or "to a lesser extent". The response that recorded the highest percentage increase was "average". At the same time, participants in the control group have become less aware of what they feel in different situations. If at the time $\mathrm{T} 0-35 \%$ of them said they were very conscious at the time $\mathrm{T} 1$, the percentage dropped by $15 \%$. 


\begin{tabular}{|l|l|l|l|l|l|}
\hline $\begin{array}{l}\text { I easily manage unpleasant } \\
\text { emotions. }\end{array}$ & $\begin{array}{l}\text { To a } \\
\text { small } \\
\text { extent }\end{array}$ & $\begin{array}{l}\text { To } \\
\text { some } \\
\text { extent }\end{array}$ & $\begin{array}{l}\text { To a } \\
\text { moderate } \\
\text { extent }\end{array}$ & $\begin{array}{l}\text { To a } \\
\text { great } \\
\text { extent }\end{array}$ & $\begin{array}{l}\text { To a } \\
\text { very } \\
\text { great } \\
\text { extent }\end{array}$ \\
\hline Treatment group T0 & $7 \%$ & $20 \%$ & $33 \%$ & $20 \%$ & $20 \%$ \\
\hline Treatment group T1 & $0 \%$ & $13 \%$ & $40 \%$ & $20 \%$ & $27 \%$ \\
\hline Control group T0 & $7 \%$ & $13 \%$ & $40 \%$ & $33 \%$ & $7 \%$ \\
\hline Control group T1 & $0 \%$ & $13 \%$ & $47 \%$ & $33 \%$ & $7 \%$ \\
\hline
\end{tabular}

Regarding the statement "Easily manage unpleasant emotions", it appears that the treatment group records an increase of only $7 \%$. It is also noted that, compared with previous analysis, this time, the control group did not record a decrease but an increase. If in T0 $7 \%$ of respondents said they manage the "very little" and $40 \%$ of "average" unpleasant emotions, in T1 none of the respondents chose "to a very small extent", instead the "average" has grown by $7 \%$.

\begin{tabular}{|l|l|l|l|l|l|}
\hline Assertive communication & $\begin{array}{l}\text { To a } \\
\text { small } \\
\text { extent }\end{array}$ & $\begin{array}{l}\text { To } \\
\text { some } \\
\text { extent }\end{array}$ & $\begin{array}{l}\text { To a } \\
\text { moderate } \\
\text { extent }\end{array}$ & $\begin{array}{l}\text { To a } \\
\text { great } \\
\text { extent }\end{array}$ & $\begin{array}{l}\text { To a } \\
\text { very } \\
\text { great } \\
\text { extent }\end{array}$ \\
\hline Treatment group T0 & $7 \%$ & $13 \%$ & $13 \%$ & $40 \%$ & $27 \%$ \\
\hline Treatment group T1 & $6 \%$ & $0 \%$ & $19 \%$ & $50 \%$ & $25 \%$ \\
\hline Control group T0 & $20 \%$ & $0 \%$ & $27 \%$ & $33 \%$ & $20 \%$ \\
\hline Control group T1 & $26 \%$ & $0 \%$ & $20 \%$ & $27 \%$ & $27 \%$ \\
\hline
\end{tabular}

After analysing the responses of the participants in the two groups to the statement "Assertive communication", it is observed that within the treatment group there is an increase of several percent, while within the control group there is a decrease, which means that the participants from the treatment group 
has improved their communication skills, and the control group participants do not communicate as well. Also, within the control group, there is an increase among participants who claim to be very assertive.

\begin{tabular}{|l|l|l|l|}
\hline $\begin{array}{c}\text { Voice volume - When you are in the } \\
\text { park at the playground. }\end{array}$ & Quietly & Normal & Loud \\
\hline Treatment group T0 & $0 \%$ & $33 \%$ & $67 \%$ \\
\hline Treatment group T1 & $7 \%$ & $60 \%$ & $33 \%$ \\
\hline Control group T0 & $0 \%$ & $60 \%$ & $40 \%$ \\
\hline Control group T1 & $0 \%$ & $60 \%$ & $40 \%$ \\
\hline
\end{tabular}

Concerning the voice tonality that the participants should adopt at the playground, the treatment group also notices a change of behaviour if in T0 67\% of them choose to speak loudly in T1, only $33 \%$ of them choose to do this, most of them in a proportion of $60 \%$, choosing to speak normally. At the same time, there is no behavioural change within the control group, $60 \%$ of whom choose to speak normally and $40 \%$ speak loud.

\begin{tabular}{|l|l|l|l|}
\hline $\begin{array}{c}\text { Voice volume - You have a } \\
\text { misunderstanding with your } \\
\text { colleague. }\end{array}$ & Quietly & Normal & Loud \\
\hline Treatment group T0 & $13 \%$ & $47 \%$ & $40 \%$ \\
\hline Treatment group T1 & $20 \%$ & $53 \%$ & $27 \%$ \\
\hline Control group T0 & $29 \%$ & $57 \%$ & $14 \%$ \\
\hline Control group T1 & $33 \%$ & $60 \%$ & $7 \%$ \\
\hline
\end{tabular}


As for the voice tonality that participants should adopt when they have a misunderstanding with their colleague, the participants in the treatment group in T0, the majority, $47 \%$ would speak normally, but in a proportion almost as high as $40 \%$ would talk loudly, while in Q1 only $27 \%$ of them would scream, $53 \%$ (a 6\% increase over T0) would speak normal and 20\% (with a 7\%) would speak quietly. It is interesting to note that even within the control group changes are recorded in the same direction as in the treatment group - in T0 14\% of them would be screaming, 57\% would have spoken normal and $29 \%$ quietly, in T1 only $7 \%$ would choose to speak loudly, $60 \%$ speak normal and $33 \%$ quietly.

\begin{tabular}{|l|l|l|}
\hline \multicolumn{1}{|c|}{ I am strong if: I eat many sweets } & \multicolumn{1}{|c|}{ YES } & NO \\
\hline Treatment group T0 & $60 \%$ & $40 \%$ \\
\hline Treatment group T1 & $7 \%$ & $93 \%$ \\
\hline Control group T0 & $27 \%$ & $73 \%$ \\
\hline Control group T1 & $27 \%$ & $73 \%$ \\
\hline
\end{tabular}

As for the perception of the aspects that help the participants "to be strong" if they eat sweets, it is observed within the treatment group that the perception changes in $\mathrm{T} 1$ versus $\mathrm{T} 0$. If in $\mathrm{T} 0$ only $40 \%$ considered that sweets are not a good food, T1 increases by 53\%. By comparison, there is no change in sweat perceptions within the control group, with $73 \%$ of the participants considering that they do not help you to be strong.

\begin{tabular}{|l|l|l|}
\hline \multicolumn{1}{|c|}{ I'm strong if: I do sport regularly } & \multicolumn{1}{|c|}{ YES } & NO \\
\hline Treatment group T0 & $87 \%$ & $13 \%$ \\
\hline Treatment group T1 & $80 \%$ & $20 \%$ \\
\hline Control group T0 & $80 \%$ & $20 \%$ \\
\hline
\end{tabular}




\section{Control group T1}

$$
73 \%
$$

As for the perception of the issues that help participants "to be strong" if they do sport regularly, both the treatment group and the control group have the same situation. In both groups, the number of participants who consider that sport is beneficial drops from $\mathrm{T} 0$ to $\mathrm{T} 1$.

\begin{tabular}{|l|l|l|}
\hline I'm strong if: I rest when I feel tired & YES & NO \\
\hline Treatment group T0 & $87 \%$ & $13 \%$ \\
\hline Treatment group T1 & $93 \%$ & $7 \%$ \\
\hline Control group T0 & $80 \%$ & $20 \%$ \\
\hline Control group T1 & $87 \%$ & $13 \%$ \\
\hline
\end{tabular}

As for the perception of aspects that help participants "to be strong" if they are resting when they are tired, both the participants in the treatment group and the control group experience the same perceptions of perception. The number of participants who feel stronger if they rest when they feel tired increases from T0 to $\mathrm{T} 1$, in both cases by $7 \%$.

\begin{tabular}{|l|l|l|}
\hline $\begin{array}{c}\text { I'm strong if: I attack the ones who } \\
\text { are weaker than me. }\end{array}$ & YES & NO \\
\hline Treatment group T0 & $20 \%$ & $80 \%$ \\
\hline Treatment group T1 & $7 \%$ & $93 \%$ \\
\hline Control group T0 & $7 \%$ & $93 \%$ \\
\hline Control group T1 & $13 \%$ & $87 \%$ \\
\hline
\end{tabular}

As for the perception of aspects that help participants "to be strong" if they attack the weaker than them, the participants in the treatment group are making 
positive attitude changes. If in $\mathrm{T} 0$ only $80 \%$ of them felt they did not feel stronger if they attacked the weakest, in T1 the percentage increases by $13 \%$. On the other hand, in the control group, the situation is different, in T0 $93 \%$ of them felt they did not feel stronger if they attacked the weakest, and in Q1 the percentage dropped by $6 \%$.

\begin{tabular}{|l|l|l|}
\hline $\begin{array}{l}\text { I'm strong if: I go the doctor to check } \\
\text { my health }\end{array}$ & YES & NO \\
\hline Treatment group T0 & $60 \%$ & $40 \%$ \\
\hline Treatment group T1 & $73 \%$ & $27 \%$ \\
\hline Control group T0 & $67 \%$ & $33 \%$ \\
\hline Control group T1 & $73 \%$ & $27 \%$ \\
\hline
\end{tabular}

As for the perception of aspects that help participants "to be strong" if they go to a doctor to check their health both within the treatment group and within the control group, there are differences in the same direction. In T1 there is an increase in the number of participants who consider that the regular doctor checks make them stronger, but the highest increase is recorded by the treatment group, $13 \%$ compared to the control group, $6 \%$.

\begin{tabular}{|l|l|l|}
\hline $\begin{array}{l}\text { Which of the following behaviours } \\
\text { helps you have a good health: Sleeps } \\
\text { between 7 and 9 hours per night }\end{array}$ & YES & NO \\
\hline Treatment group T0 & $60 \%$ & $40 \%$ \\
\hline Treatment group T1 & $80 \%$ & $20 \%$ \\
\hline Control group T0 & $93 \%$ & $7 \%$ \\
\hline Control group T1 & $93 \%$ & $7 \%$ \\
\hline
\end{tabular}

Regarding the attitudes of participants when it comes to behaviours that help them have good health in situations such as: sleeping between 7 and 9 hours per 
night, positive changes are only recorded within the treatment group. In T0, only $60 \%$ of them considered that 7-9 hours of sleep per night contributed to good health, and in T1 their number increased by $20 \%$. There are no changes in the control group, with a large majority, $93 \%$ considering that $7-9$ sleep is beneficial for good health.

\begin{tabular}{|l|l|l|}
\hline $\begin{array}{l}\text { Which of the following behaviours } \\
\text { helps you have a good health: I eat } \\
\text { regularly breakfast }\end{array}$ & YES & NO \\
\hline Treatment group T0 & $93 \%$ & $7 \%$ \\
\hline Treatment group T1 & $80 \%$ & $20 \%$ \\
\hline Control group T0 & $87 \%$ & $13 \%$ \\
\hline Control group T1 & $87 \%$ & $13 \%$ \\
\hline
\end{tabular}

Regarding the attitude of the participants when it comes to behaviours that help them have a good health in situations such as: taking regular breakfast, as in the case above, changes are only recorded within the treatment group. This time, in $\mathrm{T} 1$, the number of participants who consider regular breakfast to help good health drops by $13 \%$ compared to $\mathrm{T} 0$. There are no changes in the control group, $87 \%$ consider that taking regular breakfasts contributes to good health.

\begin{tabular}{|l|l|l|}
\hline $\begin{array}{l}\text { Which of the following behaviours } \\
\text { helps you have a good health: I to } \\
\text { sports regularly }\end{array}$ & YES & NO \\
\hline Treatment group T0 & $87 \%$ & $13 \%$ \\
\hline Treatment group T1 & $87 \%$ & $13 \%$ \\
\hline Control group T0 & $87 \%$ & $13 \%$ \\
\hline Control group T1 & $87 \%$ & $13 \%$ \\
\hline
\end{tabular}


As regards the attitude of the participants when it comes to behaviours that help them have good health in situations such as: they exercise regularly, both the treatment group and the control group have no changes, much, the percentages are identical in all four situations.

\begin{tabular}{|l|l|l|}
\hline $\begin{array}{l}\text { Which of the following behaviours } \\
\text { helps you have a good health: I do } \\
\text { not drink alcohol }\end{array}$ & YES & NO \\
\hline Treatment group T0 & $53 \%$ & $47 \%$ \\
\hline Treatment group T1 & $60 \%$ & $40 \%$ \\
\hline Control group T0 & $60 \%$ & $40 \%$ \\
\hline Control group T1 & $60 \%$ & $40 \%$ \\
\hline
\end{tabular}

As regards participants' attitudes when they refer to behaviours that help them have a good health status in situations such as alcohol consumption, changes are only recorded within the treatment group. The number of participants who consider that alcohol consumption does not contribute to good health decreases by $7 \%$ in T1. It is also noted that the percentages obtained in T1 for the treatment group are identical to those obtained in both $\mathrm{T} 0$ and $\mathrm{T} 1$ for the control group.

\begin{tabular}{|l|l|l|}
\hline $\begin{array}{c}\text { Which of the following behaviours } \\
\text { helps you have a good health: I walk } \\
\text { in the nature }\end{array}$ & YES & NO \\
\hline Treatment group T0 & $73 \%$ & $27 \%$ \\
\hline Treatment group T1 & $80 \%$ & $20 \%$ \\
\hline Control group T0 & $100 \%$ & $0 \%$ \\
\hline Control group T1 & $100 \%$ & $0 \%$ \\
\hline
\end{tabular}

Regarding the attitude of the participants when it comes to behaviours that help them have good health in situations like: I walk in nature, only within the 
treatment group there is an increase of $7 \%$ of $\mathrm{T} 0$ in $\mathrm{T} 1$ of the participants who think walking in nature helps to help you have a good health. Among the participants in the control group there are no changes, both in T0 and T1 they consider, in a $100 \%$ proportion, that walking in kind contributes to good health.

\begin{tabular}{|l|l|l|}
\hline $\begin{array}{l}\text { Which of the following behaviours } \\
\text { helps you have a good health: I'm } \\
\text { going to regular medical check-ups }\end{array}$ & YES & NO \\
\hline Treatment group T0 & $47 \%$ & $53 \%$ \\
\hline Treatment group T1 & $67 \%$ & $33 \%$ \\
\hline Control group T0 & $60 \%$ & $40 \%$ \\
\hline Control group T1 & $80 \%$ & $20 \%$ \\
\hline
\end{tabular}

Regarding the attitudes of participants when it comes to behaviours that help them have good health in situations like: going to regular medical check-ups, there are changes in both groups. Note that both in the treatment group and in the control group, the percentage of those who feel that such an attitude is beneficial in order to have good health is the same $-20 \%$.

\begin{tabular}{|l|l|l|l|l|l|}
\hline $\begin{array}{l}\text { Check to what extent (from 1- very } \\
\text { little, to 5 - very much) you know } \\
\text { and practice the good skills for your } \\
\text { health: I protect myself from risks } \\
\text { and dangers }\end{array}$ & 1 & 2 & 3 & 4 & 5 \\
\hline Treatment group T0 & $0 \%$ & $13 \%$ & $20 \%$ & $47 \%$ & $20 \%$ \\
\hline Treatment group T1 & $0 \%$ & $13 \%$ & $13 \%$ & $40 \%$ & $34 \%$ \\
\hline Control group T0 & $0 \%$ & $12 \%$ & $19 \%$ & $31 \%$ & $38 \%$ \\
\hline Control group T1 & $0 \%$ & $7 \%$ & $27 \%$ & $33 \%$ & $33 \%$ \\
\hline
\end{tabular}


As far as the level of knowledge and its application is concerned on various topics, such as: I protect myself from risks and dangers, there is a difference in both the control group and the treatment group. As a result of the data analysis, participants in the tract group are more aware of the risks and dangers and are protected from them. At the same time, within the control group some participants become more aware of risks and dangers and protect themselves (in T0 12\% responded with "little" and in T1 they were 7\%, in T0 $19 \%$ responded with "not much, or very little," and in T1 they were $27 \%$ ).

Interviews

Working with children at risk is provocative because their needs are broad, acute and intercourse, making it difficult to intervene punctually. The needs of the children identified by the counsellors and trainers within the project, depending on the role they play in the project, are diverse. One of the counsellors said that "children's needs are very acute in counselling and childbearing in a social direction." Among the identified problems is the need for attention, the need for affection, the need to be heard, the need for education (both in terms of compassion and information baggage), the need for understanding, and the need for freedom of movement.

In addition to the needs of the target group presented above, an important aspect is also the integration of parents into such programs, especially on the counselling side. Why? Because when the child receives counselling and begins to discover, to understand certain aspects of his life, his need to know and to be understood grows, and the presence of parents plays an essential role in the harmonious development of the child. Although the number of counselling hours has been limited, project counsellors have been asked by parents to help with advice and ideas as children have begun to open themselves to them and they did not know how to behave or how to deal with the situation concerned. Both counsellors and trainers said that although they are relatively small groups - of 10 participants - it is challenging to adapt the course so that it meets the individual needs of the participants. Also, being a limited number of counselling hours, from a certain point of view, the course opens the "Pandora's cuddle" and leaves it without continuity. Although the subject is a general one, with the methods and techniques used by the specialists, the course raises some 
questions to the children, which unfortunately, to the end of the project, are only to some extent reached. The need for continuation of the project is visible and is specified by each counsellor and trainer interviewed.

Following discussions with counsellors and trainers, they said the children's receptivity was high - with the indication that it grew gradually. At first the children were reluctant to find themselves in a new environment with people they saw for the first time, the need for accommodating was visible. In order to overcome this challenge and to be able to enter the theme of the course, the project specialists focused on knowledge and group integration exercises. Subsequently, their receptivity increased due to the following factors: the novelty of the information and the non-formal methods used in its delivery.

As far as the novelty of the information is concerned, whether we are talking about counselling or fomorous courses, the information provided has made the children so open because there were points not included in the school curriculum and the economic and social situation of the families from which it comes does not allow them to attend certain courses with fee.

In terms of the methods used, the keyword was "non-formal", teamwork was the icebreaker that children needed to overcome their shyness. Also, the games used in training, especially training, have led to increased receptivity - it was very important that they were able to immediately implement what they learned, which, unfortunately, in the system of education often does not happen.

The combination of theory and practice has greatly helped to increase the impact on beneficiaries. The councillors and trainers unanimously considered that the project had a positive impact on children as they did not have such training until the project enters. Depending on the situation of each beneficiary, courses may have a short, medium or long-term impact. For example, in the case of institutionalized children, it is almost impossible for them to follow certain nutrition and nutrition rules because they have predefined mentions not having the opportunity to change something, in which case they only remain with theoretical notions. Another factor is also the economic situation, because many of them do not afford a certain lifestyle, but they know how to combine basic foods, and this can be applyed in everyday life. 
One of the needs mentioned above relates to the education of children in their behaviour. The trainers stated that some of the beneficiaries, during the first meetings, did not know how to behave: limping, destroying the material didactic, fighting with each other, having a violent behaviour. This was more visible in a training center, with children with higher needs compared to the other center.

In the case of institutionalized children, the project specialists identified another need - the development of life skills - because under the current legislation they leave the system at the age of 18 and go from a system that offers them everything, to one in which they are alone. If "in the family" children are accustomed to receiving certain tasks, children in the state system are not accustomed to such situations, and there is a person in charge of these issues.

One aspect that both counsellors and trainers have been aware of was the lack of elementary notions in children according with their age. It has also been noticed that beneficiaries have potential, and in other circumstances (better training, parental involvement in child education) would have achieved remarkable results.

One of the major challenges faced by the trainers was capturing attention. They were forced to use different methods to be able to get them to be attentive, often giving them information that they did not know, thus enhancing their attention. Also, the use of non-formal methods has been an advantage in this respect.

The freedom to move, to play, was one of the identified needs. Although they are children and we did not expect them to play a necessity, that's how things are different in this case. Children often play on a computer, telephone, or other devices, and "classic childhood" games are becoming less and less present in their program. The trainer in the Fitness and Nutrition course says, "I felt a need for them, a thirst for play. The moment you threw a ball or other accessory I had, they were crazy."

One of the benefits of this project was that all courses were free for children, that they had all the auxiliary materials for a good class.

Regarding the evolution of the participants, counsellors and trainers consider that progression has been recorded both on the informational level (notions 
accumulated) and behavioural (development of skills such as communication, teamwork, etc.).

\section{Observations sheets}

The observation sheet wins four aspects of the courses: the attention of the participants, the observance of the tasks, the dynamics of the teamwork, the degree of involvement in the role-plays.

\section{Attention of the participants}

The participants were attentive in the course, but at the same time they were easily losing their attention. Trainers have recourse to a great many methods of grabbing attention from games to providing information from other areas that children did not know (history, geography, medicine). At the beginning the participants were attentive to everything that was happening around them because it was a new environment for them, they met new people. After being accommodated with one another, the attention to some aspects has fallen. The attention was increased when they were given work assignments and when they were supposed to work in a team. Depending on the group, the situation was different because the group dynamics were different - for example, in some groups some children knew some information which some made them even more attentive and active in the course, and others acted opposite - were not careful about that they knew certain information and did not let their colleagues pay any attention.

\section{Respecting tasks}

Work tasks have been respected most of the time. It was a great deal of how they were told what they had to do. It was also important if the task had to be done individually or in groups. In individual tasks, children were more receptive because it was easier to check their contribution, while other team members intervened in team tasks such as sympathies between team members if they knew each other or not. 


\section{CONCLUSIONS AND RECOMMENDATIONS}

Following the outcome of the three instruments used: questionnaire, interview and observation, the following aspects were observed:

Firstly, after completing the questionnaires by the two groups, there were specific cases that invalidate the hypothesis of this evaluation. These situations are: when there is no change in both the treatment group and the control group, the more the percentages in T0 are the same; when positive changes occur in both groups, increasing, percentually speaking, identically; when both the treatment group and the control group produce positive changes but in different proportions; when the $\mathrm{T} 0$ control group results are better than the results of the treatment group after completion of the courses; when results from the treatment group drop from $\mathrm{T} 0$ to $\mathrm{T} 1$, those in the control group remain unchanged.

In the first case, it is the statement "Which of the following behaviours helps you have a good health: I do regular exercise", both the beneficiaries and the controllers do not change their response (87\% responded with "YES" and $13 \%$ with "NO"). We can conclude that the two groups did not act as an indirect factor, the only factor that should have brought about a change, the training, not doing its effect. At the same time, it can be deduced that in this chapter - the importance of sport - the participants in both groups had large information baggage and were aware of the benefits of sport.

In the second case, it is the statement "Which of the following behaviours helps you have a good health: I go to regular medical check-ups", the answers given by the participants in the two groups increase identically - $20 \%$ of $\mathrm{T} 0$ in $\mathrm{T} 1$, although in T0 the two groups have different percentages. This situation highlights one thing that factors other than training have intervened. Also, if we analyse the curriculum we specify hours for a healthy life, so the percentages have grown identically in both groups because it acted the same factor, the most likely information provided during school hours.

In the third case, it is the statement "I am strong if I: I go to a doctor to control my health", there are increases in both cases, but in the treatment group the increase is higher, which means that they have acted two factors in the case of 
the first group and one factor in the control group. This theme is also addressed in the curriculum. We can deduce that the common factor was the information provided by the school.

In the fourth case, the statement "Which of the following behaviours helps you have a good health: Sleep between 7 and 9 hours per night" even though the responses within the treatment group differ positively from $\mathrm{T} 0$ in $\mathrm{T} 1$, these are lower than the results obtained by the control group in T0. This highlights the discrepancies between the level of education of children in the same class (so some have benefited from the program and others do not). It is also noticed that the needs of the participants in the two groups are different or may be the same but at a different intensity.

In the last case, it is the statement "Which of the following behaviours helps you have a good health: Take regular breakfast," in which the participants in the treatment group change their perception of the subject. The results are contrary to the objectives set in the courses.

Secondly, following the interviews, we can conclude that the project has had a positive impact on children, that their needs are acute and that they differ from one individual to another, that classrooms have approached general themes because the group's dynamics were different, and their needs. Each counsellor and trainer noticed a change among the beneficiaries, which means that the work they have submitted during the 16 hours of training and 2 counselling was visible and the tools and methods they chose applications, correlated with the information baggage delivered, have produced changes both collectively and individually.

Thirdly, following the analysis of the observations made during the training and counselling courses, the conclusions drawn from interviews with trainers and counsellors are reached. In other words, the result of the observation note comes as a second confirmation of the results of the interviews and questionnaires 


\section{RECOMMENDATIONS}

1. To better identify participants' needs in order to create targeted courses for their individual needs.

2. Increase the number of training and counselling hours in order to generate more visible and medium-term or long-term impact.

3. Introducing counselling hours for parents because they do not know how to behave in some situations with their own child, learn to be there for him.

4. Changing group dynamics - there should be no longer children with very different age groups because the level of understanding is different, as does the pace of work.

\section{REFERENCES}

- Cummings, R., 2006, What if: the counterfactual in program evaluation, Evaluation Journal of Australasia, Vol.6, no.2

- Gertler, J., P., Martinez, S., Premand, P., Rawlings, B., L., Veermersch, M., J., C., 2011, Impact Evaluation in Practice, The World Bank

- Gertler, J., P., Martinez, S., Premand, P., Rawlings, B., L., Veermersch, M., J., C., 2016, Impact Evaluation in Practice, Second Edition, The World Bank

- Shaw, F., I., Greence, C., J., Mark, M., 2006, Handbook of Evaluation - Policies, Programs and Practice, Sage

- White, H., 2009, Theory-Based Impact Evaluation: Principles and Practice, International Initiative for Impact Evaluation, Working paper 3 